\title{
Analytical Prediction of Rotor Eddy Current Loss Due to Stator Slotting in PM Machines
}

\author{
Dominic A. Wills \\ domwills@gmail.com
}

\author{
Maarten J. Kamper \\ kamper@sun.ac.za
}

University of Stellenbosch, Private Bag X1, Matieland, 7602, South Africa.

\begin{abstract}
Certain types of PM electric machines are particularly susceptible to the proliferation of eddy currents flowing within the solid conducting regions in the rotor. These eddy currents can be induced by current winding harmonics, but also by the interaction of the static rotor magnetic field with the permeance variation of the slotted stator known as 'slotting'. This work focuses on the analytical calculation of eddy current loss that occurs in the conducting regions within a rotor under no-load conditions. The results are compared with finite element analysis and measured results from a machine test. Good agreement is achieved between the three methods of comparison.
\end{abstract}

Index Terms-- permanent magnet, eddy current, losses, slotting, rotor yoke, analytical, finite element.

\section{LIST OF SYMBOLS}

\begin{tabular}{|c|c|c|}
\hline Symbol & Quantity & Unit \\
\hline A & Magnetic vector potential & V.s.m ${ }^{-1}$ \\
\hline$B$ & Flux density & $\mathrm{T}$ \\
\hline$H$ & Magnetic field strength & A. $m^{-1}$ \\
\hline$\omega_{s}$ & Stator Synchronous Frequency & radians \\
\hline$t$ & Time & $\mathrm{s}$ \\
\hline$\mu$ & Harmonic number & \\
\hline$N_{s}$ & Number of Slots & \\
\hline$l_{m}$ & Machine length & metres \\
\hline$d_{s i}$ & Stator inner diameter & metres \\
\hline$n_{s}$ & Rotor speed & $\operatorname{rad} . \mathrm{s}^{-1}$ \\
\hline$N_{p}$ & Number of poles & \\
\hline$\kappa$ & Conductivity & S.m ${ }^{-1}$ \\
\hline$R_{s}$ & Stator radius adjacent to airgap & metres \\
\hline$g^{\prime}$ & Effective airgap & metres \\
\hline$h_{y}$ & Yoke height & metres \\
\hline$\mu_{r}$ & Relative permeability & \\
\hline$J$ & Current density & A. $m^{-2}$ \\
\hline$T_{s}$ & Segment width & radians \\
\hline Ps & Magnet segmentation penetration & $\%$ \\
\hline Py & Yoke Segmentation penetration & $\%$ \\
\hline$b_{s l}$ & Slot width & radians \\
\hline$\tau_{p}$ & Pole Pitch & radians \\
\hline$r_{m c}$ & Magnet centre radius & metres \\
\hline$h_{m}$ & Magnet height & metres \\
\hline$l_{s}$ & Segment length & metres \\
\hline$N_{s s}$ & Number of Segments & \\
\hline$N_{r s}$ & Relative Degree of Segmentation & \\
\hline$\mu_{0}$ & Permeability of free space & H.m ${ }^{-1}$ \\
\hline$b_{0}$ & Stator slot opening width & radians \\
\hline$K_{w}$ & Winding factor & \\
\hline$K_{c}$ & Carter Factor & \\
\hline
\end{tabular}

\section{INTRODUCTION}

Low speed permanent magnet synchronous machines are becoming an increasingly attractive option for many applications including use in direct drive wind generators. Depending on the machine topology and design, eddycurrent induced solid loss in the conductive regions of the rotor can be a source of inefficiency in these machines. A high proportion of the literature in this field [1-10] has focused on the effect of asynchronous field harmonics caused by current in the stator windings. However, another not insignificant group of asynchronous field harmonics exist due to the interaction of the magnetic field due to the magnets, and the permeance variation due to the teeth of the stator, also known as 'slotting'. This effect of slotting on eddy current rotor losses is often ignored in literature, which is an assumption which will not hold for all design types. An open slot, surface mounted magnet machine configuration can give rise to rotor losses as large as those caused by stator winding harmonics, and therefore, in many cases cannot be ignored.

\section{ANALYTICAL MODEL}

In order to calculate the no load eddy current spatial function, one must first calculate the magnetic fields due to slotting. For the machine model, a permanent magnet synchronous machine is linearised to create the machine model in the $(\mathrm{x}, \mathrm{y}, \mathrm{z})$ plane shown in Fig. 1. The co-ordinate axes are fixed to the moving rotor reference frame. A current sheet lies on the stator surface and represents a collection of harmonics present due to the effect of slotting. The no-load magnetic fields consist of two major groups of harmonics. There are those harmonics caused by to the rotor's static magnetic field, which rotate synchronously with the rotor. The second group of harmonics arises due to the interaction of the static rotor fields and the magnetic permeance variation between the slots and teeth in the stator, which rotate asynchronously to the rotor.

The rotor magnetic flux function can be described as:

$$
\begin{gathered}
B_{r}(x, y)=\sum_{k=1,3,5 \ldots}^{\infty} B_{r e m}(y) \cos \left(k \frac{N_{p}}{2} x\right) \\
\text { where } \quad B_{r e m}(y)=\frac{4 r_{m c} B_{r e m}}{\pi N_{p} k} \sin \left(k p \Phi_{m}\right)
\end{gathered}
$$

where $r_{m c}$ represents the radius at the magnet centre.

In order for eddy currents to be induced in a conductor, there must be a relative speed between the conduction medium and the field harmonic. The group of harmonics in (1) rotates at a frequency of $2 \pi n_{s}$, which is synchronous with the rotor. However, when this static magnetic field harmonic interacts with the permeance variation in the stator, a new asynchronous set of harmonics is produced.

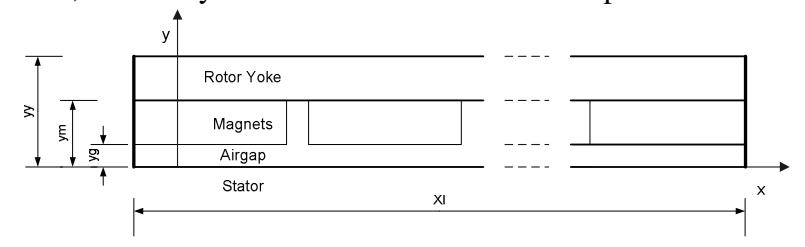

Fig. 1: The linear machine model shown in the $\mathrm{x}, \mathrm{y}$ plane. 
The permeance variation function is described in [11] in a 2-D model which uses a conformal transformation assuming a unit magnetic potential applied between the rotor and stator surfaces and assumes infinitely deep rectilinear slots. The permeance function is defined as

$$
\lambda(x, y)=\sum_{\mu=0}^{\infty} \Lambda_{\mu}(\mathrm{y}) \cos \left(\mu N_{s} x\right)
$$

where

$$
\Lambda_{0}(y)=\frac{1}{K_{c}}\left(1-1.6 \beta \frac{b_{0}}{\tau}\right) \text {, }
$$

$$
\begin{aligned}
& \Lambda_{\mu}(y) \\
& =-\beta(y) \frac{4}{\pi \mu}[0.5 \\
& \left.+\frac{\left(\mu \frac{b_{0}}{\tau}\right)^{2}}{0.78125-2\left(\mu \frac{b_{0}}{\tau}\right)^{2}}\right] \sin \left(1.6 \pi \mu \frac{b_{0}}{\tau}\right) \\
& \left.\beta(y)\right|_{y=R_{r}}=\frac{1}{2}\left[1-\frac{1}{\sqrt{1+\left(\frac{b_{0}}{2 g^{\prime}}\right)^{2}}}\right]
\end{aligned}
$$

As this calculation is only interested in the permeance variation as seen by the rotor surface, the simplified version of the $\beta(y)$ function is used, where $v=0$. Note in (4), the Carter Factor has been used in the definition of the DC permeance variation Fourier coefficient to account for the overall reduction in flux due to slotting. The definition of the Carter factor is:

$$
K_{c}=\frac{\tau}{\tau-\gamma g^{\prime}}
$$

where

$$
\begin{aligned}
\gamma=\frac{4}{\pi}\left[\frac{b_{0}}{2 g^{\prime}} \tan ^{-1}\left(\frac{b_{0}}{2 g^{\prime}}\right)\right. & \\
& \left.-\ln \sqrt{1+\left(\frac{b_{0}}{2 g^{\prime}}\right)^{2}}\right]
\end{aligned}
$$

and

$$
\tau=\frac{2 \pi R_{s}}{N_{s}}
$$

One quantifies the effect of slotting, given various slotting dimensions, by multiplying the permeance variation function by the static field created by the rotor, as

$$
\begin{aligned}
& B_{\text {rotorsurface }}(x, y) \\
& =\sum_{\mu=0}^{\infty} \Lambda_{\mu}(y) \cos \left(\mu N_{s} x_{s}\right) \\
& \times \sum_{k=1,3,5 \ldots}^{\infty} B_{\text {rem }}(y) \cos \left(k \frac{N_{p}}{2} x\right)
\end{aligned}
$$

In order to simulate the machine's movement, the rotor is defined as the stationary reference frame and the stator is moved at the negative of the rotor speed, i.e.

$$
x_{s}=x+\omega t
$$

This gives:

$$
\begin{aligned}
& B_{\text {rotorsurface }}(x, y) \\
& =\sum_{\mu=0}^{\infty} \sum_{k=1,3,5 \ldots}^{\infty} \frac{\Lambda_{\mu}(y) B_{\text {rem }}(y)}{2} \cos \left[\left(\mu N_{s}\right.\right. \\
& \left.\left. \pm k \frac{N_{p}}{2}\right) x+\mu N_{s} \omega t\right]
\end{aligned}
$$

An important highlight from a rotor loss perspective is that each space harmonic is a function of the rotor field and the stator permeance harmonic numbers. These field harmonics operate at frequencies that are asynchronous to the rotor frequency causing them to induce eddy currents. In the sections where magnetic fields in the rotor are computed, the function described by (12) is required to be expressed in terms of magnetic vector potential:

$$
\begin{aligned}
& A(x, y)=-\int B_{y} d x \\
& =-\sum_{\mu=0}^{\infty} \sum_{i=1,3,5 \ldots 2}^{\infty} \frac{\Lambda_{\mu}(y) B_{r e m}(y)}{2\left(\mu N_{s} \pm i \frac{N_{p}}{2}\right)} \sin \left[\left(\mu N_{s}\right.\right. \\
& \left.\left. \pm i \frac{N_{p}}{2}\right) x+\mu N_{s} \omega t\right]
\end{aligned}
$$

The expression for the electric field induced in a conductor is defined as the time rate of change of the magnetic vector potential, summed with a grad term which is constant in the $(x, y)$ plane, i.e.

$$
E(x, y)=-j \omega A(x, y)+\operatorname{grad} \varnothing
$$

In this work, currents will be assumed to flow only in the positive and negative $\mathrm{z}$ direction. The current density is computed as

$$
\begin{aligned}
J(x, y)=J_{z}(x, y) & =-j \omega \mathrm{K} A(x, y)+C \\
& =-j \omega \mathrm{K}\left(C_{y} e^{\gamma y}\right. \\
& \left.+D_{y} e^{-\gamma y}\right) e^{-\alpha x}+C
\end{aligned}
$$

In a solid conductor, eddy current flow is limited only by the material conductivity. Using the magnetic vector potential, harmonic frequency and conductivity, the total ohmic loss due to heat produced by eddy currents can be calculated by:

$$
P_{\text {ave }}=\frac{l_{m}}{2 \mathrm{~K}} \cdot \overline{J(x, y) \cdot J(x, y)^{*}}
$$

\section{RESULTS}

The $15 \mathrm{~kW}$ PM synchronous test generator is shown in Fig. 2, with the dimensions listed in Table I. Measurements from this machine provide the magnet and rotor yoke loss 
data that is listed in Table II. The exact method for measuring the magnet and yoke loss is outlined in the Appendix.

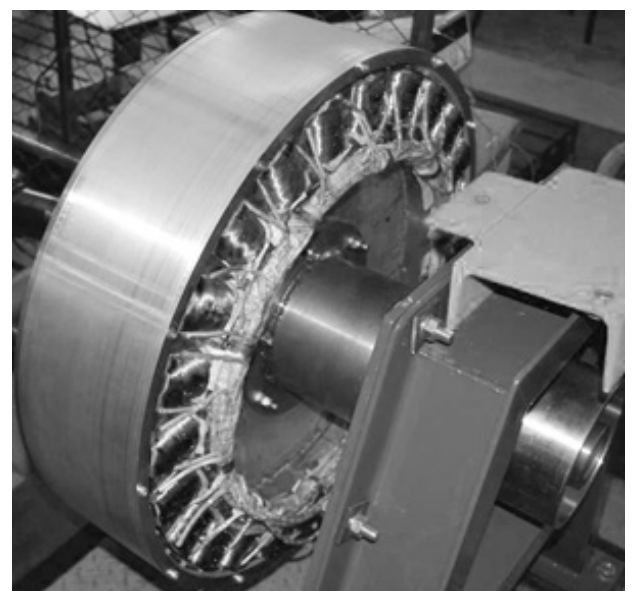

Fig. 2: The machine used for testing is seen here on a test bench.

The results of the eddy current density in the magnet for a specified machine are shown in Fig. 3. This machine is a permanent magnet machine with 40 solid magnets (poles) and 48 stator slots and a solid rotor yoke and run under no load. The two lines show the eddy current density function in the centre circumference of the solid magnets. The graph shows that an excellent agreement is achieved between the eddy current density values calculated analytically and those calculated using finite element analysis.

The next calculation uses (16) to determine the total losses in the magnets and solid rotor yoke of the machine. The results of this calculation are published in Table II. There is a good agreement between the overall results in the three machines.

TABLE I

TEST MACHINE DIMENSIONS USED FOR MEASUREMENT AND ANALYSIS

\begin{tabular}{cc}
\hline Machine Parameter & Dimension \\
Slots & 48 \\
Poles & 40 \\
Stator Inner Diameter & $247 \mathrm{~mm}$ \\
Stator Outer diameter & $311.5 \mathrm{~mm}$ \\
Rotor outer Diameter & $326.75 \mathrm{~mm}$ \\
Stack Length & $100 \mathrm{~mm}$ \\
Rotor Yoke Thickness & $7.25 \mathrm{~mm}$ \\
Magnet Pitch & $0.73 \%$ \\
Magnet thickness & $6 \mathrm{~mm}$ \\
Rated Speed & $150 \mathrm{r} / \mathrm{min}$ \\
Air gap Length & $2 \mathrm{~mm}$ \\
Coil Width & $18 \mathrm{~mm}$ \\
Tooth Width & $11.1 \mathrm{~mm}$ \\
\hline
\end{tabular}

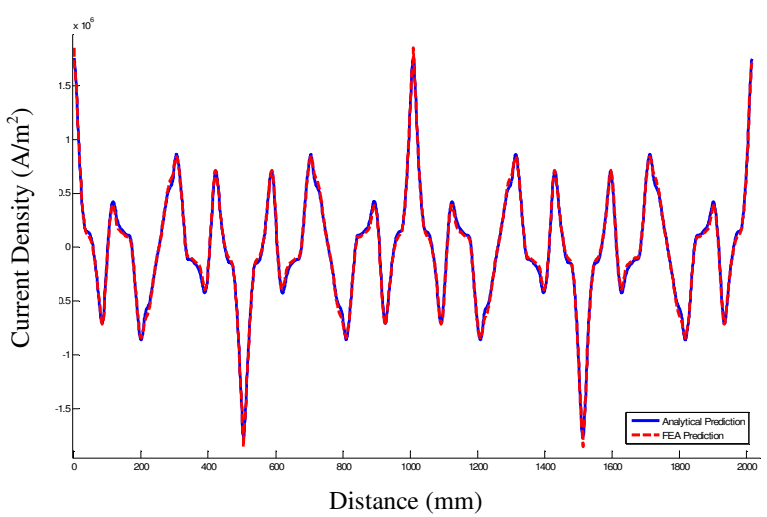

Fig. 3: Comparison of FEM and analytical calculations for eddy current density in the centre of the magnet.

TABLE II

EDDY CURRENT LOSSES INDUCED IN THE MAGNETS AND ROTOR AT NO LOAD, 150R/MIN.

\begin{tabular}{|c|c|c|c|}
\hline & $\begin{array}{c}\text { Magnet Solid } \\
\text { Loss }(\mathrm{W})\end{array}$ & $\begin{array}{c}\text { Rotor Yoke Solid } \\
\text { Loss }(\mathrm{W})\end{array}$ & Total \\
\hline Analytical & 202 & 515 & 717 \\
\hline Finite Element & 220 & 535 & 755 \\
\hline Measured & & & 733 \\
\hline
\end{tabular}

\section{CONCLUSION}

This research proposes a new analytical method of calculating solid loss in conducting regions of a rotor due to the permeance effects of stator slotting. The overall results of the computation method can be regarded as being very accurate in the case of the magnet. It should be noted however, that due to variations in steel saturation, the assumption of constant permeability in steel as set in the analytical model is not ideal. This variation can cause some accuracy loss in the analytical solution of the solid rotor yoke affects the accuracy of the result. The finite element prediction does not suffer from this drawback. Despite this, however, the analytically calculated results are still very usable, and more importantly give very valuable insight into the cause of eddy currents and how it is affected by changing machine parameters.

\section{APPENDIX}

The no load rotor loss measurement is done by comparing the losses in three different PM rotors, which was the subject of another study comparing different types of magnet segmentation. The rotors are identical in geometry, but differ in terms of magnet segmentation and rotor yoke core material as:

PM rotor 1: solid magnets and solid mild steel rotor yoke; PM rotor 2: partially segmented magnets and solid mild 
steel rotor yoke;

PM rotor 3: partially segmented magnets and a laminated rotor yoke.

For each of the three PM rotors the input shaft power, $P_{\text {in }}$ $=\omega_{s} \tau$, and the steady state outer rotor temperature, $T_{r o}$, are measured, with the PM machine each time at no load and driven at a speed of $150 \mathrm{r} / \mathrm{min}$. Assuming no hysteresis loss in the PM rotor, the first equation for the total rotor eddy current loss, $P_{e r}$, is given by

$$
P_{e r}=P_{\text {in }}-P_{\text {loss }},
$$

where $P_{\text {loss }}=P_{w f}+P_{s}$, i.e. equal to the wind and friction losses plus the core and winding eddy current losses in the stator.

In a second equation for $P_{e r}$, Newton's thermal law of cooling is considered. In the thermal model two assumptions are made. Firstly it is assumed that heat transfer takes place only through convection, thus heat transfer through radiation is ignored. Secondly, heat transfer to ambient via moving air in the air gap is ignored. With these two assumptions $P_{r r}$ can be expressed approximately as

$$
\begin{aligned}
P_{e r} & =\frac{d Q}{d t} \\
& \approx h_{o} A_{o}\left(T_{r o}-T_{a}\right)+h_{i} A_{i}\left(T_{r i}-T_{a s}\right)
\end{aligned}
$$

where $Q$ is the heat energy, $h_{o}$ and $h_{i}$ are the outer and inner rotor surface heat transfer coefficients, $A_{o}$ and $A_{i}$ are the outer and inner rotor yoke surface areas, $T_{r o}$ and $T_{r i}$ are the measured outer and inner rotor surface temperatures and $T_{a}$ and $T_{s}$ are the ambient and stator temperatures respectively. It was found during measurements that $T_{s} \approx T_{a}$ and that $T_{r i} \approx$ $T_{r o}$, so that (18) can be simplified as

$$
\begin{aligned}
P_{e r} & \approx\left(h_{o} A_{o}+h_{i} A_{i}\right)\left(T_{r o}-T_{a}\right), \\
& =h A\left(T_{r o}-T_{a}\right)
\end{aligned},
$$

From (17) and (19) three equations can be obtained for the three PM rotor measurements assuming $P_{\text {loss }}$ stays constant, namely as

$$
\begin{aligned}
& P_{\text {in }(1)}-P_{\text {loss }} \approx h A\left(T_{r o}-T_{a}\right)_{1} \\
& P_{\text {in }(2)}-P_{\text {loss }} \approx h A\left(T_{r o}-T_{a}\right)_{2}, \\
& P_{\text {in }(3)}-P_{\text {loss }} \approx h A\left(T_{r o}-T_{a}\right)_{3}
\end{aligned}
$$

where subscripts 1, 2 and 3 refer to PM rotor $1, \mathrm{PM}$ rotor 2 and PM rotor 3 respectively as described above. From (20) on average the constants $P_{\text {loss }}$ and $h A$ can be determined. With these constants known $P_{e r}$ can be determined by (17) or (19).

\section{REFERENCES}

1. Kais Atallah, David Howe, Philip H. Mellor, and David A. Stone, "Rotor Loss in Permanent-Magnet Brushless AC Machines", IEEE Transactions On Industry Applications, Vol. 36, No. 6, November/December 2000

2. Z.Q. Zhu, K. Ng, N. Schofield and D. Howe, "Improved analytical modelling of rotor eddy current loss in brushless machines equipped with surface mounted permanent magnets", IEE Proc.-Electr. Power Appl., Vol. 151, No. 6, November 2004

3. Hiroaki Toda, Zhenping Xia, Jiabin Wang, Kais Atallah, David Howe, "Rotor Eddy-Current Loss in Permanent Magnet Brushless Machines", IEEE Transactions On Magnetics, Vol. 40, No. 4, July 2004
4. Dahaman Ishak, Z. Q. Zhu, David Howe, "Eddy-Current Loss in the Rotor Magnets of Permanent-Magnet Brushless Machines Having a Fractional Number of Slots Per Pole", IEEE Transactions on Magnetics, vol. 41, no. 9, September 2005

5. H. Polinder, M.J. Hoeijmakers, M. Scuotto, "Eddy-Current Losses in the Solid Back-Iron of PM Machines for different Concentrated Fractional Pitch Winding", IEEE International Electric Machines \& Drives Conference, 2007. IEMDC '07, Volume 1, 3-5 May 2007, p. $652-657$

6. Jason D. Ede, Kais Atallah, Geraint W. Jewell, Jiabin Wang, David Howe, "Effect of Axial Segmentation of Permanent Magnets on Rotor Loss in Modular Permanent-Magnet Brushless Machines", IEEE Transactions on industry applications, Vol. 43, no.5, September/October 2007.

7. Miroslav Markovic, Yves Perriard, "Analytical Solution for Rotor Eddy-Current Losses in a Slotless Permanent-Magnet Motor: The Case of Current Sheet Excitation”, IEEE Transaction on Magnetics, Vol. 44, No.3 March 2008.

8. Nicola Bianchi, Michele dai Pre, Luigi Alberti, Emanuele Fornasiero, "Theory and design of Fractional-Slot PM Machines", September 2007.

9. Peter Sergeant, Alex van den Bossche, "Segmentation of Magnets to Reduce Losses in Permanent-Magnet Synchronous Machines", IEEE Transactions on Magnetics, Vol. 44 No. 11, November 2008.

10. Z.Q. Zhu, K. Ng, N. Schofield and D. Howe, "Improved analytical modelling of rotor eddy current loss in brushless machines equipped with surface mounted permanent magnets", IEE Proc.-Electr. Power Appl., Vol. 151, No. 6, November 2004

11. D. Howe, Z.Q. Zhu, "Instantaneous Magnetic Field Distribution in Brushless Permanent Magnet dc Motors, Part III: Effect of Stator Slotting", IEEE Transactions on Magnetics, Vol. 29, No.1, January 1993

12. R. Nuscheler, "Comparison of Permanent Magnet Synchronous Machines with Distributed and Concentrated Windings", ICEM 2006, XVII International conference on Electrical Machines, paper no. 609, 2-5 September 2006, Crete Island, Greece.

13. R. Nuscheler, "Two-Dimensional Analytical Model for Eddy Current Loss Calculation in the Magnets and Solid Rotor yokes of Permanent Magnet Synchronous Machines", Proceedings of the 2008 international conference on Electric Machines, Paper ID 1095

14. Nicola Bianchi, Emanuele Fornasiero, "Impact of MMF Space Harmonic on Rotor Losses in Fractional-Slot Permanent-Magnet Machines", IEEE Transactions on energy conversion, Vol. 24, No.2, June 2009. 